\title{
Aa. Vv., «Bulletin des Amis d'André Gide», n. 140
}

\section{Emanuele Kanceff}

\section{Q OpenEdition}

\section{Journals}

\section{Edizione digitale}

URL: https://journals.openedition.org/studifrancesi/39728

DOI: 10.4000/studifrancesi.39728

ISSN: 2421-5856

\section{Editore}

Rosenberg \& Sellier

\section{Edizione cartacea}

Data di pubblicazione: 1 décembre 2004

Paginazione: 406-407

ISSN: 0039-2944

\section{Notizia bibliografica digitale}

Emanuele Kanceff, «Aa. Vv. «Bulletin des Amis d'André Gide», n. 140», Studi Francesi [Online], 143 (XLVIII | II) | 2004, online dal 30 novembre 2015, consultato il 19 mai 2021. URL: http://

journals.openedition.org/studifrancesi/39728 ; DOI: https://doi.org/10.4000/studifrancesi.39728

Questo documento è stato generato automaticamente il 19 mai 2021.

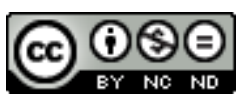

Studi Francesi è distribuita con Licenza Creative Commons Attribuzione - Non commerciale - Non opere derivate 4.0 Internazionale. 


\title{
Aa. Vv., «Bulletin des Amis d'André Gide», n. 140
}

\author{
Emanuele Kanceff
}

\section{NOTIZIA}

«Bulletin des Amis d'André Gide», n. 140, année XXXVI e, vol. XXXI, octobre 2003, pp. 425-464.

1 Gide et l'enfance, di David STEEL (pp. 433-443) affronta, in apertura di volume, un tema complesso e delicato. Delle varie direzioni d'indagine possibili, l'A. ne sceglie tre: Gide e la nozione dell'infanzia; Gide a cospetto dei bambini e particolarmente della sua bambina Catherine; Gide e la sua infanzia in senso biografico.

2 Vi è in Gide, ed è stato spesso notato, un atteggiamento infantile che permane anche nell'età matura. Nel suo Journal, Gide trentaseienne esprimerà molto nettamente questa realtà: «Mai sarò un uomo, io non sarò altro che un bambino invecchiato». Così pure, la simpatia che nutre per il gioco infantile, il ricorso all'immagine infantile per la descrizione dei suoi personaggi, gli esempi frequenti di reductio ad infantilem, le conclusioni delle sue opere narrative con l'introduzione di un nuovo personaggio fanciullo, sono tutti indizi concordanti di questa sua particolare predilezione.

3 Una fittissima analisi dei passaggi significativi dell'opera in questo senso induce l'A: nella convinzione condivisa con lo scrittore che Gide fosse un uomo-fanciullo, osservatore dell'infanzia, assillato dall'infanzia, in preda a pulsioni deleterie ma che facevano anche di lui una sorta di vittima dell'infanzia, nella qual situazione innocenza e colpevolezza si intrecciavano.

$4 \quad$ LIU Ke rievoca Quatre-vingts ans de présence d'André Gide en Chine (pp. 445-457) prendendo le mosse da un passaggio dei suoi Essais critiques e dal senso totale di alterità che l'immagine della Cina evoca per lo scrittore. A partire dall'inizio del Novecento le opere di Gide in Cina hanno avuto due periodi di interesse durati ciascuno un ventennio e ora la fortuna continua, anche se molte delle sue opere sono ancora ignorate. Ciò che 
soprattutto deve essere evitato è la superficialità di vetrina con cui da molto pubblico in Cina lo scrittore è ancora conosciuto.

5 Segue una preziosa bibliografia cinese di Gide.

6 Stephen STEELE presenta poi una lettera inedita di Jean Malaquais su Gide (André Gide dans ls souvenir de Jean Malaquais, pp. 459-465). Segue un articolo di Thomas REISEN su Citations, allusions et références dans "L'Immoraliste" (pp. 467-484) e un saggio di Karine GERMONI su "Saül" ou la réécriture gidienne du mythe biblique (pp. 485-501). Infine, chiude la serie il lavoro di Anton ALBLAS, che costituisce la seconda parte del saggio L'Euvre instantanée: le "Journal" d'André Gide. Questa parte porta il titolo di La genèse du "Journal".

7 Una nuova puntata del Journal di Robert LEVESQUE termina il volume, con il consueto seguito di recensioni e documenti 